\title{
SUJEITO PROTOPÁTICO: O EU ILUSÓRIO E O AFETO EM QUESTÃO
}

\author{
Sérgio Eduardo Prudente \\ Miriam Debieux Rosa
}

\begin{abstract}
RESUMO. Partindo do questionamento feito por André Green acerca do lugar do afeto no psiquismo, retomando o termo sujeito protopático proposto por Lacan, este texto propõe um percurso fazendo um paralelo entre este autor e Nietzsche, filósofo que tem o afeto um ponto crucial em seu pensamento. Para isso, a discussão pauta-se no campo onde há uma interpretação auto-enunciadora do afeto, a saber, o Eu, e a própria experiência afetuosa. Este Eu para os dois autores é uma instância ilusória, porosa, e imersa em um auto-engano enquanto o afeto assume estatuto fundamental. Apesar de possuir qualidades diferentes para cada autor, o afeto converge para uma noção de Saber que, para além do Eu, consiste na maneira de lidar com o pathós num campo que prescinda dos juízos ilusórios.
\end{abstract}

Palavras-chave: Afeto; eu; ilusão.

\section{PROTOPATHIC SUBJECT: THE EGO ILLUSION AND THE AFFECT IN QUESTION}

\begin{abstract}
From the questioning by André Green about the place of affection in the psyche, resuming the term subject protopathic proposed by Lacan, this paper propose a path by drawing a parallel between this author and Nietzsche, a philosopher who has affection as a crucial point in his thinking. To do this, the discussion is focused in the field where there is a statement of the interpretation of self-affection, namely Ego, and the very affectuous experience. This Ego is, the two authors, an illusory body, porous, and immersed in a self-deception as the affection assumes fundamental status. Despite having different qualities for each author, the affect converges to a notion of knowledge that, beyond the Ego, is the way to deal with the pathós in a field that dispenses illusory judgments.
\end{abstract}

Key words: Affection; ego; illusion.

\section{SUJETO PROTOPÁTICO: EL EGO ILUSÓRIO Y EL AFECTO EN CUESTIÓN}

RESUMEN. Partiendo del cuestionamento hecho por André Green acerca del lugar del afect en la psique, a través de la palabra sujeto protopático tema propuesto por Lacan, este texto propone un percurso haciendo un paralelo entre este autor y Nietzsche, filósofo que tiene el afecto como un punto crucial en su pensamiento. Para esto, la discusión se pauta en el campo donde ha una interpretación autoenunciadora del afecto, entender, el Yo, y la propia experiencia afectuosa. Este Yo para los dos autores es una instancia ilusoria, porosa, y inmersa en un auto engaño mientras el afecto asume estatuto fundamental. A pesar de tener cualidades diferentes para cada autor, el afecto converge para una noción del saber que, para mas allá del Yo, consiste en el modo de se relacionar con el pathos en el campo que prescinde de juicios ilusorios.

Palabras-clave: Afecto; yo; ilusión.

\footnotetext{
Doutorando em Psicologia Social (Núcleo de Psicanálise e Política) pela PUC-SP (Bolsista FAPESP), com estágio na Unité Transversale de Recherche Psychogenèse et Psychopathologie - Université Paris 13 - Nord (Bolsista CAPES).

\# Doutora em Psicologia Clínica pela PUC-SP, docente do departamento de Psicologia Social da PUC-SP, onde dirige o Núcleo da Psicanálise e Política, docente do departamento de Psicologia clínica da Universidade de são Paulo, USP, onde dirige o laboratório de Psicanálise e Sociedade.
} 
André Green (1982), em um comentário acerca do lugar do afeto na obra de Jacques Lacan, retoma o termo sujeito protopático, para questionar o lugar do afeto no psiquismo:

embora seja verdade que o campo freudiano não leva em consideração o "sujeito protopático", este juízo é cada vez mais contestável à medida que nos aproximamos das últimas formulações de Freud que destronam o inconsciente em favor do Id. Além disso, as aquisições preciosas do pensamento psicanalítico pós-freudiano evidenciam se não o sujeito protopático, pelo menos o lugar do afeto na atividade psíquica (p. 120).

Green nos coloca com sua observação uma questão espinhosa, a de um sujeito do afeto primordial. Para isso, ele se apóia nas formulações sobre o Id e nas pesquisas de alguns pós-freudianos. $\mathrm{O}$ questionamento de Green nos convida a pensar sobre uma espécie de caráter ontológico que o sujeito protopático possui, pensado a partir do Id como fonte dos afetos. Podemos depreender disto um par profundidade/superfície que pode nos levar para um entendimento de "um afeto mais verdadeiro" ou "mais profundo", na medida em que ele é primordial; por esta senda teríamos que considerar então, algo como uma essência afetiva, o que transmutaria a profundidade/superfície na velha questão filosófica da essência/aparência. Neste sentido, o que podemos entender como protopático?

$\mathrm{O}$ termo protopático vem da junção do antepositivo grego prôtos $^{l}$, que indica a condição de anterioridade, de estar à frente ou em primeiro e ainda do principal, com a palavra também grega pathós que denota uma qualidade ou experiência ligada ao sofrimento, à sensação e à afecção. Portanto, o sujeito protopático aponta para um estado primeiro de afecção, ou um primeiro afeto sentido pelo sujeito. Esta definição seria simples se não possuísse um detalhe contido nas palavras afeto e sujeito. Se o afeto é sentido pelo sujeito, logo, podemos inferir que o sujeito vem antes do afeto? Podemos inferir ainda que existe um sujeito que, por vir antes do afeto, não sente? Estado improvável levando-se em conta as próprias terminações nervosas do corpo.

Partir da etimologia do termo sujeito protopático é uma estratégia proposital, pois ela nos fornece condições de situar alguns campos responsáveis pelas escolhas feitas neste texto. Primeiro, nos remetendo à palavra sujeito, logo nos encontramos com o autor

1 Prôtos e pathós segundo o dicionário Houaiss de língua portuguesa. que foi alvo da crítica de Green, a saber, Jacques Lacan. Este autor foi o responsável pela introdução e delimitação conceitual do termo sujeito na psicanálise, e ainda, foi de sua obra que Green recortou o termo "sujeito protopático". Por outro lado, ao tratar de afeto, pathós, essência/aparência e Id, abrimos a possibilidade de costura conceitual na qual nos fica sugerido um autor da filosofia que é, por vezes, vinculado a psicanálise, ou seja, Friedrich Nietzsche. Dessa forma, a proposta deste texto é fazer uma discussão a respeito do sujeito protopático e alguns elementos que o envolvem, a partir do campo conceitual que tentaremos estabelecer. Nietzsche e Lacan são nossos convidados para discutir esse sujeito do afeto com a habilidade de enunciar um "eu sinto". Tentaremos evitar uma "filosofização" da psicanálise ou uma "psicanalisação" da filosofia; o desafio aqui é tentar interrogar um autor que comumente é acusado de renegar o afeto em sua teoria (Lacan) e outro autor que tem o afeto um ponto central em seu pensamento (Nietzsche). Ao final, faremos um breve comentário sobre o estatuto desse sujeito protopático e suas conseqüências conceituais para a aparência, ontologia, e o afeto. Optamos em iniciar com uma apresentação a partir de Nietzsche para em seguida dar a vez para Lacan. As apresentações seguem o vetor do afeto/Eu/realidade ilusória que nos serviu de recorte para tratar desse tema.

\section{NIETZSCHE - O AFETO FUNDAMENTAL E O EU ILUSÓRIO}

Ilusório, porém firme. - assim como, para passar junto a um princípio ou cruzar uma frágil ponte sobre um rio profundo, necessitamos de um corrimão, não para nos agarrar a ele - pois logo se romperia conosco -, mas para despertar na visão a idéia da segurança, assim também precisamos, quando jovens, de pessoas que inconscientemente nos prestem o serviço daquele corrimão. É verdade que elas não nos ajudariam, se realmente nos apoiássemos nelas em caso de perigo, mas dão a impressão tranqüilizadora de que há uma proteção ao lado (os pais, professores e amigos, por exemplo, tais como são normalmente os três) (Nietzsche, 1878/2005, p. 320).

Neste trecho, Nietzsche nos fornece alguns elementos para pensar. $\mathrm{O}$ rio profundo, logo de início, nos conota uma vertigem, uma iminência de perigo ou morte ante a algo desmedidamente (rio profundo) mais poderoso que nós mesmos. A frágil ponte ou um princípio é o que nos resta para lidar com esse Outro 
que a qualquer momento pode nos engolir. No entanto, a frágil ponte possui um atributo que nos fornece uma ilusão, o corrimão, que nos dá idéia de segurança, mesmo que falsa, pois a "ilusão pode acarretar em mais sofrimento que a realidade" (Benoit, 2007, p. 20). Este corrimão para Nietzsche está em pais, professores, amigos.

Ao observarmos o aforismo 19 de Além do Bem e do Mal, encontraremos o "eu" como um conceito sintético responsável por conclusões errôneas. Neste sentido, podemos aproximar o eu ao corrimão da frágil ponte na medida em que ele dá a ilusão de segurança como suporte da vontade que impulsiona a travessia e suporte dos afetos que fustigam o homem que faz a passagem. $\mathrm{O}$ eu como dimensão de iludir e iludir-se faz parte de uma análise do livre-arbítrio que Nietzsche perpetra nesse livro e que tem como aspectos principais a vontade e o afeto.

Lembremos que em Além do Bem e do Mal, Nietzsche faz um crítica ao preconceito dos filósofos que fundamentam seus sistemas em concepções de certeza sustentadas por um sujeito diretamente ligado e dependente do seu predicado. Descartes, Schopenhauer e Kant são os principais alvos de Nietzsche. Sua crítica visa, sobretudo, estremecer as bases nas quais se apóiam as questões da vontade, da verdade e do livre-arbítrio.

Dessa forma, Nietzsche propõe uma vontade baseada em três aspectos que formam um complexo: as sensações, a reflexão e o afeto como o principal dele. Mas ele adverte para um detalhe: "Em terceiro lugar, a vontade não é só um complexo de sentir e pensar, mas, sobretudo, além disso, um afeto: precisamente o do comando" (Nietzsche, 1886/2000, p. 23). Nietzsche apresenta uma característica principal do afeto, a saber, a sua disposição ao comando. No entanto, algumas coisas precisam ser esclarecidas em relação ao afeto ${ }^{2}$.

Nietzsche ataca as ditas "certezas imediatas". Para isto ele parte de princípios que integram a própria linguagem e forma como ela media a realidade para o homem. O "eu penso" cartesiano e o "eu quero" shopenhauriano são os pontos de partida para o desvelamento de uma ilusão. "Devemos nos libertar da sedução das palavras", o "eu penso" ou o "eu quero" estabelecem uma possibilidade de o conhecimento poder se desvencilhar do objeto como "coisa em si". Para Nietzsche isto é uma falsificação tanto pela parte do sujeito como pela parte do objeto:

Advirto que em Nietzsche não há uma teoria dos afetos de tal modo que possamos encontrá-la pronta; todavia, podemos depreender dos seus livros uma compreensão que nos forneça um chão para nos firmarmos. Para isto, temos que nos deixar conduzir pelo movimento do seu pensamento.
Quando eu analiso o processo expresso na proposição "eu penso" obtenho uma série de afirmações temerárias difíceis, se não impossíveis de fundamentar. Afirmações do tipo: que sou eu que pensa, que tem de existir em absoluto algo que pensa, que pensar é uma atividade e o efeito de um ser considerado como causa, que existe um "eu", enfim, que já estabelecido o que se deve entender por pensar, que eu sei o que é pensar (Nietzsche, 1886/2000, p. 20)

O "eu penso" explicita um enunciado que pressupõem duas dimensões: a primeira está na própria individuação de um eu exteriorizado do "mim mesmo" e do mundo, a segunda é que isto se dá em uma relação de comparação com outros estados conhecidos do "mim" como elemento subjetivo diferenciado do exterior e que se objetiva em um "eu penso" ou "eu quero". No bojo dessa crítica segue a questão da pura forma buscada numa estética de um Belo que agrada sem interesse tal como expressa no sexto parágrafo da Genealogia da Moral (1887/1998, p. 86). Nietzsche aponta para um interesse sensual que há nas formas que é fundamento do interesse estético do agrado ou do desagrado na contemplação. Podemos circunscrever este "eu" fundado na certeza idealista no mesmo campo, ou seja, o "eu" como um recurso interpretativo capaz de se isolar do "interesse" sensual dos instintos deslocando o corpo como Grande Razão, como "núcleo interpretativo fundamental" (Alvarenga, 2010, p. 423).

Nietzsche nos propõe um problema gramatical.

$\mathrm{Na}$ relação sujeito/predicado temos "eu" sujeito do predicado "quero". Dois elementos que se associam para marcar um enunciado com sentido. Entretanto, Nietzsche considera uma falsificação a colocação do "eu" (sujeito) como condição do "penso" (predicado). Ao tirar o sujeito "eu" como condição do predicado poderíamos pensar que "algo" pensa, mas nem isso basta, pois, por si só, "algo" já é interpretação. A função intelectiva aglutinada no "eu" "nada produziu senão erros ... continuamente herdados, até se tornarem quase patrimônio fundamental da espécie humana" (Nietzsche, 1882/2001, p. 137) que progressivamente transmutaram a verdade para uma questão de antiguidade de conceitos retificados.

O "querer" só possui unidade como palavra e, mais ainda, sua dimensão subjetiva só alcança um estatuto através dos sujeitos nominais ou pronominais (nomes, ou pronomes pessoais, por exemplo). Por trás dessa palavra há uma pluralidade de sensações que tendem de um estado do qual queremos nos afastar para um estado ao qual queremos alcançar. O "eu", logo, não perde seu caráter de unidade, pois resulta de múltiplos instintos que engendram uma constante luta 
no interior do homem. Portanto, o "eu" concentra uma multiplicidade de várias "subvontades, ou "subalmas" que lutam por uma hierarquia de quem manda e obedece segundo um vetor que vai do "afastar" para o "chegar" concomitantes a uma sensação muscular que entra em jogo no querer. $\mathrm{O}$ que podemos denominar como "eu" é justamente o resultado desse embate movido pela vontade de poder.

Esta vontade, lembremos, tem como característica principal o afeto de comando. Aqui o "livrearbítrio"ganha outra dimensão. De uma liberdade da vontade como uma espécie de propriedade inata e pura em relação ao corpo ${ }^{3}$, agora temos um sentimento de liberdade da vontade que é precisamente a transposição metafísica desse afeto do comando. Assim, "aquilo que se denomina de "livre-arbítrio" é essencialmente o afeto de superioridade em relação àquele que deve obedecer. "Eu sou livre, 'ele' deve obedecer." (Nietzsche, 1886/2000, p. 49) O estado de comando do afeto age de acordo com a certeza íntima de obediência do objeto cuja escolha e valoração é dada na tensão da atenção, do olhar que o elegem e atribui valor.

Nietzsche, ao colocar o afeto como comando na vontade, estabelece uma afecção que se dá por uma espécie de relação de objeto, ou seja, se escolhe pela reflexão, um objeto baseado na certeza do "eu quero" e que funciona na relação do "eu sou livre" (penso, quero, etc.), "ele deve obedecer" (ser meu objeto). O curioso dessa observação é que Nietzsche considera uma forma de conflito de forças intra-psíquicas que funcionam dentro dessa lógica de domínio dos domínios das forças. Cito Nietzsche: "um homem que quer, ordena a algo dentro de si, que obedece, ou que ele julga que obedece" (Nietzsche, 1886/2000, p. 46).

Portanto, dentro de nós há os que comandam e há os que obedecem, que segundo a compreensão de Brusotti (2010), constitui uma espécie de jogo de ação/reação que separa o Nobre do escravo ressentido pela necessidade que este último tem de reagir. Às forças que obedecem resta lançar mão de recursos como "as sensações de constrangimento, da obrigação, da pressão, da resistência, do movimento" que acompanham o ato da vontade.

$\mathrm{O}$ "Eu" entra como uma ilusão que passa por cima dessa dualidade de forças, deslizando em uma cadeia de falsas valorizações da vontade, como destaca

No Segundo capítulo do primeiro livro da Crítica da Razão Prática, Kant (1788/n.d.) escreve sobre o livre-arbítrio: "para o qual, em verdade, não pode ser facultada nenhuma intuição de todo correspondente, mas que tem como base uma lei prática a priori, coisa que não se encontra em nenhum conceito de uso teórico de nossa faculdade de conhecer" (p. 53). Ou seja, o livre-arbítrio baseia-se em uma "vontade pura que existe na razão" (p. 53).
Oliveira (2010), com caso da compaixão, que na verdade, não passa de uma salvação de si no outro. Poderíamos dizer que este "eu" engendra uma falsa tradução do "livre-arbítrio". Da complexidade presente na tensão entre os impulsos que obedecem a comandos, através do "eu", passamos para uma vontade que tem seu julgamento de liberdade baseado na ilusão do "eu". Assim o "eu" não é nada além de um constante giro no circuito dos afetos que denotam o caráter insustentável que os instintos dão a todo enunciado baseado do idealismo do sujeito da certeza, a saber, o "eu". O que podemos chamar de sujeito em Nietzsche nada mais é que:

A terminologia de nossa crença numa unidade entre todos os momentos diferentes de um sentimento supremo de realidade: entendemos essa crença ao ponto que, por amor dela, imaginamos a "verdade, a "realidade", a "substancialidade". - "Sujeito" é a ficção que deseja fazer crer que diversos estados iguais são em nós o efeito de um mesmo substratum: mas fomos nós que criamos a "igualdade entre esses" diferentes estados. O igualá-los e o acomodá-los, eis os fatos e não a igualdade ( - é mister, ao contrário, negar a igualdade - ) (Nietzsche, 1902/1945, p. 287).

$\mathrm{Na}$ medida em que este sujeito resulta de uma crença ou amor à verdade, ou à realidade que pressupõe uma unicidade de estados, Nietzsche aponta para um problema ontológico. Por esta via, pensamos com Viesenteiner (2010) quando propõe uma leitura nietzscheana de um sujeito como contingência do real ou efeito do mundo, ou seja, cultivado na experiência (Erlebnis) que o faz amar o destino e tornar-se o que se é. Este sujeito seria então um somatório das conjunturas que contribuem para uma determinada precipitação que se reconhece como "sujeito" e capaz de enunciar via um "eu penso". Por isso, não existiria nenhuma substância a ser invocada como sua origem, como um a priori. O "eu" em Nietzsche é, sobretudo, demiurgo de si mesmo: "L'effet c'est moi" (Nietzsche, 1886/2000, 49).

Que ninguém dá ao ser humano suas propriedades; nem Deus, nem a sociedade, nem seus pais e ancestrais, nem ele mesmo (o contra-senso da representação, aqui por fim recusada, é ensinado por Kant, e talvez mesmo já em Platão, como "liberdade inteligível”). Ninguém é responsável em geral por ele existir, por ser constituído de tal ou tal modo, por ele se encontrar sob estas circunstâncias, nessa ambiência. A fatalidade de sua existência não pode ser separada da 
fatalidade de tudo o que foi e de tudo o que será (Nietzsche, 1888/2000, p. 50).

\section{LACAN - O AFETO PELO SIGNIFICANTE E O EU COMO FUNÇÃO DE DESCONHECIMENTO}

No campo freudiano, apesar das palavras, a consciência é um traço tão caduco, para basear o inconsciente em sua negação (esse inconsciente data de são Tomás), quanto o afeto é incapaz de desempenhar o papel do sujeito protopático uma vez que esse é um cargo que não tem titular ali (Lacan, 1966/1998, p. 813).

Parto desta consideração feita por Lacan para tentar definir um campo do afeto diante da ilusão de um Eu que desconhece a si mesmo. Na citação Lacan indica que o afeto não é capaz de desempenhar o papel do sujeito protopático, o que isto nos diz? Será que o sujeito protopático que se constitui concomitantemente com o afeto?

Diante desta confusão é fácil entender por que Lacan afirma que não há titular nesse cargo (de sujeito protopático). Mas isso não implica dizer que o afeto seja deixado de lado (fato apontado por Green), pelo contrário. Para melhor esclarecer esta idéia são necessárias algumas considerações a respeito do sujeito e do afeto.

Em Televisão, Lacan (1974/2003) nos diz:

o que se deve pesar é se minha idéia de que o inconsciente é estruturado como uma linguagem permite verificar mais seriamente o afeto - do que a idéia expressada de que ele é um tumulto em que se produz uma disposição melhor (p. 523).

A estratégia lacaniana é tentar alinhar-se com a concepção presente na segunda teoria freudiana da angústia em que, de efeito do recalque, a angústia passa para causa do recalque. No entanto, a reflexão lacaniana defende a angústia como afeto por excelência no seu estado bruto de um mutismo irrepresentável ou não-simbolizável enquanto tal. $\mathrm{O}$ afeto irrepresentável desloca-se; é o que podemos ler ainda em Televisão: "o afeto é deslocado. Como se julgaria esse deslocamento, a não ser pelo sujeito que se supõe por ele não aparecer ali nada melhor do que pela representação?" (Lacan, 1974/2003, p. 523).

Aqui é importante lembrar os princípios de funcionamento do inconsciente por metonímia e metáfora. Na metonímia temos a combinação de significantes sem acréscimo de sentido e que instala uma falta na própria significação proveniente da relação com o objeto. a conexão de significante com o significante que permite a elisão mediante a qual o significante instala a falta do ser na relação de objeto, servindo-se do valor de envio da significação para investi-la com o desejo visando a falta que ele sustenta (Lacan, 1966/1998, p. 519).

Neste sentido a falta a ser movimenta-se na esteira da própria metonímia do desejo, mas sem ganho de significação. Este ganho se dará pela metáfora onde é na "substituição do significante pelo significante que se produz um efeito de significação que é de poesia ou criação, ou, em outras palavras, do advento da significação em questão" (Lacan, 1966/1998, p. 519).

Com a estrutura de linguagem, temos dois níveis articulados, a saber, o corpo e a linguagem. Esta distinção é fundamental para entendermos como o lugar do sujeito protopático é vazio. Para Lacan, o corpo habita a linguagem de um jeito que algo resta e volta tentando se situar na significação. Nesta habitação o afeto não encontra um alojamento ao seu gosto (Lacan, 1974/2003, p. 526).

A relação de corpo e linguagem implica em uma castração engendrada por uma Lei que leva a termo uma dupla castração: castração do Outro e do sujeito. A castração é da ordem simbólica e visa um objeto: o falo. O falo falta na imagem e advém como referência significante privilegiada da marca através da qual se unem sexualidade e linguagem, indicando como a marca da linguagem produz um sujeito.

Ou seja, o sujeito fruto da articulação entre sexualidade e linguagem só o é pelo significante. Dessa forma, o páthos é conseqüência também do significante na medida em que a afecção só alcança um atributo auto-reflexivo que distingue o corpo, o ser, o objeto de paixão, ou de dor, a partir da referência da linguagem: "No falo se resume o ponto de mito onde o sexual se faz paixão do significante" (Lacan, 2001/2003, p. 410). Aqui entramos no campo da ontologia do ser instaurada pela paixão que busca a relação sexual.

A paixão por padecer no significante, faz do falo obstáculo à relação sexual, inscrevendo a disjunção, a desproporção. Em 1964, Lacan (1992) nos diz que "a hiância do inconsciente é pré-ontológica" (p. 32); neste sentido o ôntico é a própria fenda produzida pelo significante. Assim, a Lei do significante é a causa do sujeito ao produzir a hiância, o furo ao qual se tentará assintoticamente tapar. É por isso que o inconsciente "não é nem ser nem não-ser, mas é algo de nãorealizado". Neste sentido o desejo encontra seu limite, o ponto que mantém o "não-realizado" do inconsciente na medida em que o princípio do prazer regula no desejo a proporção de prazer que impede a realização. 
A metáfora do nome do pai no lugar correlato ao pai morto da horda primitiva socializa o desejo. No entanto, como provém do significante do nome-do-pai, ela não deixa o seu caráter dissonante na medida em que este significante marca um lugar vazio. O Pai permite a identificação com um significante puro desprovido de força que o vincule diretamente a significação. É impossível a escrita da Coisa, isto implica dizer que o ponto onde se constitui o sujeito caracteriza-se por uma impossibilidade auto-reflexiva (não existe Outro do Outro, não há metalinguagem...) e não por uma diferenciação por oposição ao "não sou".

O estatuto ôntico é também um estatuto temporal ao qual podemos situar o sujeito dentro de uma historicidade. $\mathrm{O}$ que poderíamos pressupor como uma imanência no sujeito lacaniano, proveniente deste corpo que habita a linguagem, se torna consequência de uma impossibilidade de identificação primeira do significante com a Coisa que ele cinge. Cabe dizer que propor tal constituição do sujeito implica em afirmar, para além de uma ontologia, uma lógica do significante que opera através da ausência/presença e sobre a qual a ontologia se dá. A Coisa não é idêntica a nada, ou seja, por ela a identificação não se dá, nem muito menos não há nada que a identifique a não ser o estranhamento do irrepresentável situado na hiância pré-ontológica do inconsciente.

Lacan (1959-1960/2000), ao levar em consideração a Coisa como uma espécie de âmago da economia libidinal, coloca o alvo natural da pulsão em relação a Das Ding e permanece com a idéia freudiana de pulsão sem um objeto natural. Dessa forma, a pulsão só se dá mediante a intervenção da representação. Podemos concluir, a partir disso, que há uma negatividade sobre a qual se assenta o objeto. Assim o objeto figura como uma especificação de direções que acenam para a pulsão como possibilidade de alcançar seu alvo.

Falo em possibilidade propositalmente, pois este termo dá a idéia de manter em deslocamento o movimento de busca que anima o desejo. O objeto da pulsão se mantém sempre com um caráter de "não realização" do desejo prefigurando um lugar de vazio de algo que foi perdido.

Esta perda se transforma em causa, ou melhor, causa do desejo. Lembremos que em Subversão do sujeito e dialética do desejo (Lacan, 1966/1998, p. 821), Lacan aponta que na submissão do sujeito ao significante, onde falta um ato que lhe garanta a certeza, este sujeito só pode contar com sua própria antecipação na composição do significante. Assim, o sujeito só se constitui ao se subtrair na relação com o Outro, ao desempenhar uma função de falta. O sujeito no seu pseudo-ser de $a$, se perde para se tornar causa.
Notem que o termo antecipação tem um valor fundamental na teoria lacaniana. Em Estádio do espelho Lacan nos fala de um "drama cujo impulso interno precipita-se da insuficiência à antecipação" (Lacan, 1966/1998, p. 100). Ora, o que se antecipa é a imagem do eu identificada à imago do semelhante. Neste sentido, podemos entender melhor o próprio título do texto que escreve este estádio como formador da função do eu (Je). O que Lacan nos diz já nesse texto é que há uma afetação no processo de antecipação do sujeito, isto fica indicado na própria “assunção jubilatória de sua imagem especular”.

É interessante notar que do júbilo da imagem especular, experiência auto-erótica, o eu passa para um "escoadouro da mais íntima agressividade" (Lacan, 1966/1998, p. 823) na medida em que na imagem fixada do eu-ideal, se detém o ideal-de-eu. O estádio do espelho permite "conceber a renovação dessa possibilidade sempre aberta ao sujeito, de um auto-quebramento, de um auto-dilaceramento, de uma auto-mordida, diante daquilo que é ele mesmo e o outro" (Lacan, 1960-1961/1992, p. 341). Ser "ele mesmo e o outro" abre uma dimensão de conflito que tem como saída a tolerância da imagem do outro como arrebatadora de si mesmo ou a agressão a essa imagem, a fim de inverter o jogo e conservar o "centro da pulsão de seu ser, evocado na imagem do outro" (Lacan, 1960-1961/1992, p. 341).

Até aqui, podemos entender este eu tendo uma espécie de função mediadora de afetos (o júbilo e a agressividade direcionada ao semelhante exemplificam isto). Eu este que possui imagem ilusória que mascara um duplo que se divide em uma imagem ideal (Ideal-de-eu) e uma imagem real refletida no espelho (eu-ideal) que garante a consciência de uma existência própria. Ao ser tomado a partir da imagem do outro, o eu assume uma função de desconhecimento. Neste ponto, podemos apontar mais um afeto ligado ao eu: a angústia.

Mantendo a posição freudiana de angústia como sinal, Lacan aponta para a ligação deste afeto com o objeto de desejo.

\footnotetext{
... a angústia se produz topicamente no lugar definido por i(a), isto é, como é articulado pela última formulação de Freud, no lugar do eu, mas só há sinal de angústia na medida em que ele se relaciona com um objeto de desejo, na medida em que este último perturba, precisamente o eu ideal, i(a), originado na imagem especular (Lacan, 1960-1961/1992, p. 352).
}

O sinal da angústia se produz no lugar do eu i(a). Todavia, vimos o terreno movediço que é este eu, imagem do outro, função de desconhecimento, 
imagem real refletida no espelho côncavo. Já desde o Estádio do espelho, a imagem do corpo, suporte do eu, é considerada o primeiro objeto do sujeito. O sinal da angústia vem no lugar dessa imagem quando há a iminência de sua dissolução.

Lacan alerta para esta relação entre angústia, desejo e eu através do modelo inusitado dos animais de bando. $\mathrm{O}$ animal mais esperto (Lacan fala de gazelas ou antílopes) é o que monta guarda e fica sempre atento ao perigo. Ao perceber a ameaça, o animal emite um sinal de alerta e todos os outros partem na mesma direção que o animal que sinalizou. Com a angústia acontece o mesmo, no entanto, é de um alter ego do outro que constitui o eu que vem o sinal. Disso Lacan conclui que "para cada sujeito ... o inimigo do bando é ele mesmo" (Lacan, 19601961/1992, p. 355).

Mas em que circunstância se dispara o sinal de angústia neste sujeito que é inimigo íntimo de si mesmo? Viola e Vorcaro (2009, p. 876) asseveram que "esse caos é organizado no estádio do espelho com o advento da i(a), quando o bebê adquire uma primeira noção de eu através da imagem unificada de seu corpo" assim podemos dizer que o sinal da angústia se dá na medida em que o eu se relaciona com o objeto de desejo que perturba o eu-ideal i(a) da imagem especular. Ou seja, ao se deparar com o desejo, o sujeito se confronta com o que lhe afeta e que escapa ao seu eu.

$\mathrm{O}$ papel fundamental do desejo em relação à angústia aponta para a intervenção do significante no afeto. É necessário que algo do sujeito, ou melhor, do sujeito do significante, esteja envolvido na experiência para que o sinal da angústia dispare. No seminário dedicado à Angústia, Lacan (1962-1963/1994) introduz a concepção desse afeto a partir do objeto "a", circunscrevendo-o na dimensão do real que, como destaca Sales (2008, p. 2) é "algo não-integrável pelo sujeito, encarna o vazio em que ele pode se reconhecer e se substitui, em função, ao significante que, em resposta ao desejo de reconhecimento do sujeito, só o reenviava a outro significante". É a ameaça da falta desta falta constitutiva que deflagra a angústia. Agora temos a angústia não mais do objeto de desejo, mas do objeto causa do desejo.

A angústia agora será interpelada através do desejo do Outro cuja ausência de imagem especular faz enigma Che voui? para o sujeito. Diante desse Outro, Lacan (1962-1963/1994, p. 14) evoca a figura do louva-a-deus fêmea gigante e a apreensão da possibilidade de estar usando uma máscara imprópria que pudesse induzir sua parceira ao erro sobre sua identidade, pois ele não poderia ver o próprio reflexo de sua máscara nos olhos do louva-a-deus. Assim, na função de desconhecimento da própria máscara ele pode ser objeto sexual do louva-a-deus e, ao mesmo tempo, objeto de seu gozo - não podemos esquecer que as fêmeas louva-a-deus devoram o macho depois da cópula - morto depois do ato. No desconhecimento da própria máscara, no encontro com o Outro do qual se é objeto, a angústia sinaliza no sujeito.

Ante ao que foi exposto, podemos observar que Lacan se posiciona em relação ao afeto sem colocá-lo como um acometimento primordial. A partir disto, entendemos a posição de Lacan ao dizer que o lugar do sujeito protopático não tem titular, ou seja, não há um afeto primeiro e original na ordem dos fatos psíquicos. O afeto, em sua formação, se articula com outros fenômenos, sem, contudo, ter um caráter de anterioridade; nesse sentido, ele não pode ser pensado antes da instauração do sujeito e nem mesmo fora do campo da linguagem. O sujeito é verificado no corte da cadeia significante como uma "descontinuidade no real" (Lacan, 1966/1998, p. 815):

Vez por outra, tentei dizer o que o afeto não
é. Ele não é o ser, dado em seu imediatismo,
nem tampouco o sujeito sob forma bruta. Não
é protopático em nenhum caso. Minhas
observações ocasionais sobre o afeto não
querem dizer outra coisa (Lacan, 1962-
1963/1994, p. 23).

$\mathrm{Na}$ sua relação com o desejo, o sujeito padece por ser condenado à impossibilidade de completar e ser completado. Como nos lembra Colette Soller (2011):

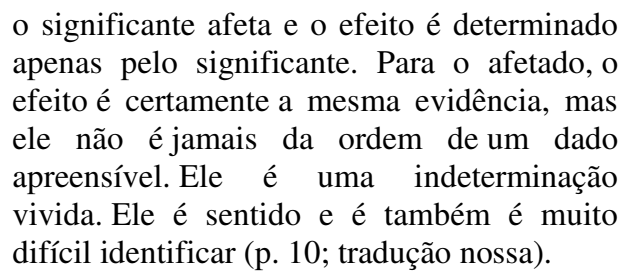

Portanto, o significante é a marca da dimensão da paixão pelo objeto, sempre miragem do engano.

\section{CONCLUSÃO}

Talvez o grande problema do sujeito protopático seja o lugar do afeto em relação ao campo do real do corpo, do orgânico e do campo do simbólico e da reflexão. Penso que poderíamos situar o afeto como uma espécie de dobradiça que revela o duplo. Neste sentido, encontramos o que Rosset (1988) aponta como uma fragilidade que revela a efemeridade da qualidade ontológica do Ser. De um lado o que vem do outro (ou Outro) que organiza uma "essência" em um valor de verdade, e do outro a duplicidade agora 
interiorizada e diferenciada do exterior que se enuncia como um "eu".

Nota-se que Lacan converge com Nietzsche no que se refere a um "eu" como ilusão e desconhecimento. Ambos não negam uma individuação psíquica de tal forma que poderíamos chamá-la de sujeito (lembro que Nietzsche não conceitua o sujeito como Lacan, assim tomo este termo de maneira genérica), contudo, este "eu" é apenas um "conceito sintético ilusório" que não comporta o saber da vontade de poder. O sujeito protopático a partir de uma leitura nietzscheana é problemático, pois, o pathós fundamental e primordial é também parte da interpretação do mundo na medida em que a vida orgânica passa à vontade de vida. $\mathrm{O}$ problema do protopático, por esta via, é que podemos considerar o afeto fundamental como protopático, mas por outro lado, a vida, o orgânico, não comporta esta protopatia por não absorver o que entendemos como vontade. Neste sentido, o sujeito protopático só o é pela interpretação em Nietzsche, ou pelo significante em Lacan.

O "eu" da certeza é ilusão de transcendência ao basear-se no idealismo da pura forma, Themi (2008) aborda este aspecto pela maneira como a ética da psicanálise - Seminário número 07 proferido por Lacan em 1959-1960 - complementa a crítica nieztscheana ao platonismo. Por essa via, ante ao real, a certeza ilusória do "eu" engana-se no seu livrearbítrio por fazer desse o engano de um controle da vontade. O gaio saber em Nietzsche é o do Isso, do fluxo conflituoso da vontade de poder e de vida que não se reconhece numa unidade auto-enunciadora. Nem por isso, o autor nega a capacidade do pensamento, pelo contrário, o afeto entra juntamente neste entreposto entre vida e reflexão. Saúde e doença passam, por isso, a serem categorias da interpretação subsumidas na qualidade dos afetos que podem resistir e enfraquecer o homem, ou afirmar sua qualidade de comando.

A versão do gaio saber em Lacan é o gaio issaber (gay sçavoir) (Lacan, 2001/2003, p. 525). É interessante notar que o gaio saber nietzscheano tem um caráter virtuoso e prodigioso diante do perigo. Aponto para isto, pois o gaio issaber lacaniano também fala de uma virtude que não absolve ninguém do pecado. A virtude manifestada no gaio issaber é, como propõe Bousseyroux (2009), ética. Ela consiste em não fisgar o sentido, não compreender, mas resvalar tão perto possível sem ter que colar nele. $\mathrm{O}$ gaio issaber é queda que goza com o deciframento.

O gaio issaber não é redutível à opacidade de uma emoção circunscrita nas profundezas do ser, nem de uma substância insondável do sensível, ele atrela-se a um saber que é, sobretudo, o do Isso - instância impessoal, que pela linha Nietzsche/freudiana, contêm o real saber em detrimento ao $E u$, instância ilusória e auto-iludida. Ou seja, Isso pensa!

A manifestação afetiva do gaio issaber está, segundo Lacan, no pólo oposto ao da tristeza, que por sua vez é considerada um índice de covardia moral. Assim, o que está em jogo no gaio issaber é uma maneira entusiasta de afirmação diante do ângulo morto que dita as coordenadas das referências infinitas da demanda do outro. Ou melhor, da afecção exercida pelo Outro na forma de padecimento do Real do qual o sujeito é efeito. Lacan (1974/2003) nos diz:

\begin{abstract}
No pólo oposto da tristeza existe o gayoissaber [gay sçavoir] o qual, este sim, é uma virtude. Uma virtude não absolve ninguém do pecado - original, como todos sabem. A virtude que designo como gaio issaber é o exemplo disso, por manifestar no que ela consiste: não em compreender, fisgar [piquer] no sentido, mas em roçá-lo tão de perto quanto se possa, sem que ele sirva de cola para essa virtude, para isso gozar com o deciframento, o que implica que o gaio issaber, no final, faça dele apenas a queda, o retorno ao pecado. (p. 525)
\end{abstract}

Tal virtude não absolve ninguém do pecado, não se refere a renuncia do desejo nem a um equilíbrio de forças, mas uma estratégia de reinscrever o desejo para além da culpa, das dívidas, recriminações e ruminações caras ao posicionamento no sintoma do neurótico. Desta forma, temos um modo de acolher o pathós, excesso do gozo e assujeitamento ao Real, sem recorrer à compreensão que torna o sentido uma espécie de cola que adere às significações que convocam as ilusões egóicas.

O pathós, diferentemente do patológico do doente, não regressa ao infantil, nem condensa gozo em um nó significante, onde, do recalque, produz sintoma. Na paixão, ou melhor, no pathós, há sempre a dor de um padecer (ou pade-Ser...) que impõe desafios que muitas vezes buscamos enfrentar pela recusa da dor. Tal pathós permite ao vivido elevar-se a uma forma que pode ser apreendida, abrindo uma nova via que não as habituais formas de satisfação do desejo. Esta forma não aspira a nenhuma finalidade. Neste sentido, na paixão do Ser, tanto em Nietzsche como em Lacan, propõe-se transformar o padecer em vir-a-ser.

\section{REFERÊNCIAS}

Alvarenga, R. (2010). Nietzsche e o corpo. Estudos Nietzsche, Curitiba, 2(1), 423-428. 
Benoit, B. (2007). Meio-dia; instante da mais curta sombra. Cadernos Nietzsche, 23, 7-27.

Bousseyroux, M. (2009). Éthique du gay sçavoir. L'en-je lacanien, 13(2), 192. Editeur ERES.

Brusotti, M. (2010). Reagir e não reagir: filosofia e psicologia no Crepúsculo dos ídolos. Estudos Nietzsche, Curitiba, 2(1), 373-388.

Green, A. (1982). O discurso vivo: uma teoria psicanalítica do afeto. (R. J. Dias, Trad.). Rio de Janeiro: Francisco Alves.

Kant, I. (1788/n. d.). Crítica da Razão Prática. Rio de Janeiro: Edições de Ouro (Coleção Universidade).

Lacan, J. (1992). O Seminário. Livro VIII. A Transferência. Rio de Janeiro: Jorge Zahar Editor. (Original publicado em 1960-1961).

Lacan, J. (1992). O Seminário. Livro XI. Os Quatro conceitos fundamentais da Psicanálise. Rio de Janeiro: Jorge Zahar Editor. (Original publicado em 1964).

Lacan, J. (1994). O Seminário. Livro X. A Angústia. Rio de Janeiro: Jorge Zahar Editor. (Original publicado em 1962-1963).

Lacan, J. (1998). Escritos. Rio de Janeiro: Jorge Zahar Editor. (Original publicado em 1966).

Lacan, J. (2000). O Seminário. Livro VII. A Ética da Psicanálise. Rio de Janeiro: Jorge Zahar Editor. (Original publicado em 1959-1960).

Lacan, J. (2003). Outros Escritos. Rio de Janeiro: Jorge Zahar Editor. (Original publicado em 2001).

Lacan, J. (2003). Televisão. In Outros Escritos (pp. 508543). Rio de Janeiro: Jorge Zahar Editor. (Original publicado em 1974).

Nietzsche, W. F. (1878/2005). Humano demasiado humano. São Paulo: Companhia das Letras. (Original publicado em 1878).

Nietzsche, W. F. (1882/2001). Gaia Ciência. São Paulo: Companhia das Letras. (Original publicado em 1882).

Nietzsche, W. F. (1886/2000). Além do Bem e do Mal. São Paulo: Companhia das Letras. (Original publicado em 1886).
Nietzsche, W. F. (1888/2000). Crepúsculo dos Ídolos. Rio de Janeiro: Relume Dumará. (Original publicado em 1888).

Nietzsche, W. F. (1945). Vontade de potência. Tradução de Mário D. Ferreira Santos. Rio de Janeiro: Edição da Livraria do Globo. (Original publicado em 1902).

Nietzsche, W. F. (1998). Genealogia da Moral: uma polêmica. São Paulo: Companhia das Letras. (Original publicado em 1887).

Oliveira, J. R. (2010). A crítica de Nietzsche à moral da compaixão de Schopenhauer em Aurora: o desprezo de si como artimanha de condenação do indivíduo. Revista Voluntas: Estudos sobre Schopenhauer, 2 (1), 04-22.

Rosset, C. (1988). O Real e seu Duplo. São Paulo: L\&PM Editores S/A.

Sales, L. S. (2008). Para além do desejo de nada: o objeto a como resistência ao plano transcendental dos significantes na psicanálise lacaniana. Revista de Estudos Lacanianos, 2(1), 295-311.

Soller, Colette. (2011). Les affects Lacaniens. Paris: PUF.

Themi, Tim. (2008). How Lacan's Ethics might improve our understanding of Nietzsche's Critique of Platonism: the neurosis \& nihilism of a "Life" against life. Cosmos and History: The Journal of Natural and Social Philosophy, 1-2 (4).

Viesenteiner, J. L. (2010) "Cultivo" e Vivência (Erlebnis): Premissas à Construção da Tarefa de "Tornar-se o que se É" em Nietzsche. Cadernos de Ética e Filosofia Política 17 (2), 203-227.

Viola, D. T. D., \& Vorcaro, A. M. R. (2009). A formulação do objeto a a partir da teorização lacaniana acerca da angústia. Revista Mal-estar e SubjetividadeFortaleza. 3 (9), 867-903.
Endereço para correspondência:
Sérgio Eduardo Prudente. Rua Paulistânia, nº 466, Bairro: Sumarezinho, CEP 05440-001, São Paulo-SP, Brasil. E-mail: sergio_prudente@yahoo.com.br. 